\title{
An Automated Blood Pressure Display for Self-Measurement in Patients With Chronic Kidney Disease (iHealth Track): Device Validation Study
}

Victoria Mazoteras-Pardo ${ }^{1 *}$, MSc, PhD; Ricardo Becerro-De-Bengoa-Vallejo ${ }^{{ }^{*}}, \mathrm{BSc}$, MLIS, DPM, PhD, DHL; Marta Elena Losa-Iglesias $^{2^{*}}, \mathrm{PhD}, \mathrm{BSc}, \mathrm{MsC}$, DP; Daniel López-López ${ }^{3 *}, \mathrm{PhD}, \mathrm{BSc}$, MsC, DP; César Calvo-Lobo ${ }^{{ }^{*}}, \mathrm{PhD}$, PT, MSc; David Rodríguez-Sanz ${ }^{1 *}, \mathrm{PhD}, \mathrm{MsC}, \mathrm{PT}, \mathrm{DP}$; Eva María Martínez-Jiménez ${ }^{4 *}$, PhD, BSc, MsC, DP; Patricia Palomo-López ${ }^{*}, \mathrm{PhD}, \mathrm{MsC}, \mathrm{DP}$

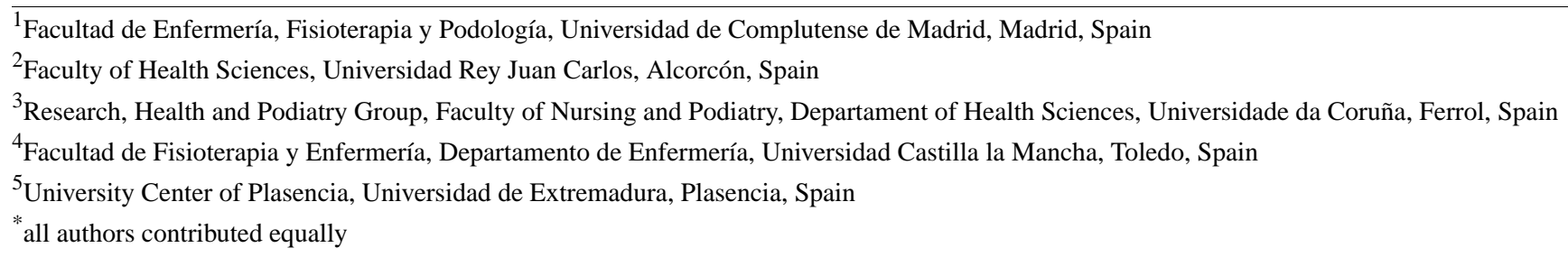

Corresponding Author:

Daniel López-López, PhD, BSc, MsC, DP

Research, Health and Podiatry Group

Faculty of Nursing and Podiatry, Departament of Health Sciences

Universidade da Coruña

Campus Universitario de Esteiro S/N

Ferrol, 15403

Spain

Phone: 34981337400 ext 3546

Email: daniellopez@udc.es

\section{Abstract}

Background: Hypertension is a global public health issue and is closely related to chronic kidney disorder (CKD). In people with CKD, strict monitoring of blood pressure is an important part of therapy.

Objective: The aim of this research was to validate the iHealth Track blood pressure monitoring device for patients with CKD according to the European Society of Hypertension International Protocol 2010 (ESH-IP2).

Methods: In total, 33 patients who received hemodialysis in Plasencia participated in the study. There were 9 successive measurements made, which conformed to the ESH-IP2. We calculated the differences between the standard reference device (Omron M3 Intellisense) and the test device (iHealth Track) for blood pressure and heart rate values. For 99 total comparisons of paired measurements, we classified differences into various categories $(\leq 5 \mathrm{mmHg}, \leq 10 \mathrm{mmHg}$, and $\leq 15 \mathrm{mmHg}$ for blood pressure; $\leq 3, \leq 5$, and $\leq 8$ beats per minute for heart rate).

Results: In 90 of 99 systolic blood pressure and 89 of 99 diastolic blood pressure comparisons between the devices, measurement differences were within $5 \mathrm{mmHg}$. In 81 of 99 heart rate comparisons between the devices, measurement differences were within 3 beats per minute. The mean differences between the test and reference standard measurements were 3.27 (SD 2.99) mmHg for systolic blood pressure, 3.59 (SD 4.55) $\mathrm{mmHg}$ for diastolic blood pressure, and 2.18 (SD 2.75) beats per minute for heart rate. We also observed that for both systolic and diastolic blood pressure, 31 of 33 participants had at least two of three comparisons between the devices with measurement differences less than $5 \mathrm{mmHg}$. For heart rate, 28 of 33 patients had at least two of three comparisons between the devices with measurement differences less than 3 beats per minute.

Conclusions: To our knowledge, this is the first study to show that iHealth Track meets the requirements of the ESH-IP2 in patients with CKD. Therefore, the iHealth Track is suitable for use in renal patients.

(JMIR Mhealth Uhealth 2020;8(4):e14702) doi: $\underline{10.2196 / 14702}$ 


\section{KEYWORDS}

iHealth Track; validation; blood pressure; heart rate; International Protocol

\section{Introduction}

Chronic kidney disorder (CKD) is a syndrome defined by persistent alterations in renal function or structure that cause complications in a patient's health. Some of the structural anomalies may be tumors, cysts, malformations, or atrophies. In addition, renal dysfunction can be manifested through alterations in the output or grade of urine, increased risks of intellectual disabilities in children, edema, and hypertension $[1,2]$.

In fact, the diseases most related with CKD are hypertension and diabetes, especially in high- and middle-income countries $[3,4]$. Hypertension may simply be a consequence of CKD $[5,6]$ or both a cause and consequence of CKD [7,8]. Hypertension may be due to hypervolemia or activation of the renin-angiotensin system or neurohumoral (catecholamine and aldosterone) axis. In addition, sometimes high blood pressure (BP) originates from calcineurin or corticosteroid inhibitors used to treat underlying kidney disorders [9].

The interaction between CKD and hypertension is complex and increases the probability of cerebrovascular and cardiovascular problems [9-11]. In several studies, cardiovascular events and deaths from any cause were reduced when systolic BP was $<120$ mmHg (compared to $<140 \mathrm{mmHg}$ ) in patients with CKD and hypertension but not diabetes [11-13]. Therefore, strict control of BP is important for CKD therapy [14].

Monitoring of BP should be done with devices that are easy to use and accurate [11,15-18]. These devices must be tested and validated by independent experts (eg, the British Hypertension Society [19], the Association for the Advancement of Medical Instrumentation [20], and the European Society of Hypertension $[21,22])$ with protocols validated and designed expressly for BP monitoring [23]. The purpose of this study was to validate the iHealth Track BP monitoring device for self-measurement in patients with CKD, according to the European Society of Hypertension International Protocol 2010 (ESH-IP2). Therefore, the hypothesis of this study was that iHealth Track would be valid for the self-measurement of BP and heart rate (HR) in renal patients according to the ESH-IP2.

\section{Methods}

\section{Ethical Information}

The study protocol was approved by the Institutional Local Research and Ethical Committee (Universidad de Extremadura, Badajoz, Spain; record number 152/2019). In conducting this study, we complied with the ethical principles of the Declaration of Helsinki [24], including any emendations between 2000 and 2013. All participants provided signed informed consent prior to participating in this study.

\section{The Devices}

\section{Omron M3 Intellisense}

The standard device we used for reference was the Omron M3 Intellisense (Omron Healthcare, Kyoto, Japan), which has been validated according to the International Protocol for the general population [25] as well as CKD patients [26]. We purchased the Omron M3 Intellisense monitor from a local marketplace. The Omron M3 Intellisense is an oscillometric and automated upper-arm device for home BP monitoring. The device's standard arm cuff is 22 to $32 \mathrm{~cm}$ around, and a large cuff is also available for arm circumferences of 32 to $42 \mathrm{~cm}$. The device uses IntelliSense technology to produce comfortable, controlled inflation without the need for pressure presetting or reinflation.

\section{iHealth Track}

The test device was the iHealth Track automatic appliance with serial number KN-550BT (iHealthLabs Europe, Paris, France), which registers brachial BP with the oscillometric protocol. It detects $\mathrm{BP}$ between the range of $0 \mathrm{mmHg}$ to $300 \mathrm{mmHg}$ (measuring precision $\pm 3 \mathrm{~mm} \mathrm{Hg}$ ) and $\mathrm{HRs}$ within the range of 40 to 180 beats per min (measurement precision $\pm 5 \%$ ). The device's arm cuff is 22 to $42 \mathrm{~cm}$ around.

The device's liquid crystal display screen shows the measured systolic (S) BP, diastolic (D) BP, and HR values. The device unit has enough memory for 99 recordings. Additionally, this device unit can be used with Apple Bluetooth 4.0 devices and certain Android Bluetooth 4.0 cellular phones through an application named Health MyVitals. This means that BP and HR data can be stored on wireless devices connected to iHealth Track and then displayed graphically.

\section{Patients and Recruitment}

We recruited patients with CKD who attended the Fresenius Medical Care dialysis clinic in Plasencia, Spain. A total of 33 patients who met the selection criteria participated. The inclusion criteria were adults 25 years of age or older that received hemodialysis. We sought at least 10 male participants and 10 female participants. The exclusion criteria, which were created according to the ESH-IP2 [21,22], were sustained arrhythmia, circulatory problems where use of the cuff is contraindicated, and pregnancy.

\section{Research Protocol}

The professional validation team consisted of 2 nurses with senior experience (more than 6 years) in BP measurement. The measurement area was correctly conditioned to a suitable temperature, and factors that could affect the records, such as noise or distractions, were removed [21,22]. All measurements were made in the same room. The color of the room was white.

After dialysis, each patient first reported information regarding their sex, age, height, and dry weight. In addition, we calculated participants' BMI using Quetelet's index in $\mathrm{kg} / \mathrm{m}^{2}$. The circumference of the patient's arm was measured to ensure that the cuff size was adequate. 
Next, patients sat in the measurement room and BP measurements were started after a 10- to 15-minute rest period. Each patient was seated in a standard-size plastic chair with a backrest and armrests.

In total, 9 consecutive measurements were made on each participant with the Omron M3 Intellisense (5) and the iHealth Track (4) as follows [21,22]:

- $\quad$ (BPA): input BP, by the standard device unit

- (BPB): device BP detection by the test device unit

- (BP1): standard device unit

- (BP2): test device unit

- (BP3): standard device unit

- (BP4): test device unit

- (BP5): standard device unit

- (BP6): test device unit

- (BP7): standard device unit

During the measurements, participants remained calm, quiet, seated, and still. Participants kept their backs straight and feet on the floor in a parallel position (ie, without crossing their legs). They rested their arms on a flat surface with their palms facing upwards and their elbows slightly flexed so that their fists were at the height of their hearts.

$\mathrm{BP}$ records were made at heart level on the right arm in 31 participants and on the left arm in 2 participants (because of an arteriovenous fistula on the right arm). The standard cuff size $(22-32 \mathrm{~cm})$ for the Omron M3 Intellisense was used for all men (20). For women, the standard cuff $(22-32 \mathrm{~cm})$ was used for 11 participants, and the large cuff $(32-42 \mathrm{~cm})$ was used for 2 participants. Since the iHealth Track has only one cuff size $(22-42 \mathrm{~cm})$, all measurements were taken with it. The interval between one measurement and the next was 30 to 60 seconds [22].

All measurements were made for each participant during their hemodialysis appointment, after the dialysis was complete. The relative values were then used to calculate the mean difference between the reference device readings and the test device readings. All participants were receiving hemodialysis in the Fresenius Medical Care dialysis clinic in Plasencia.

\section{Data Analysis}

We analyzed the data with the software SPSS Statistics, version 19.0 (IBM, Armonk, New York). We reported the findings as mean (SD).

According to the ESH-IP2, the accuracy of a device is based on a comparison between the test device (iHealth Track) and the standard reference device (Omron M3 Intellisense) measurements. For each participant, we first compared measurements BP2, BP4, and BP6 with measurements BP1, $\mathrm{BP} 3$, and BP5, respectively, and then compared measurements BP3, BP5, and BP7 with each other. The most favorable comparisons were used.

In our comparisons, we classified differences for both SBP and DBP, separately, by whether paired values were within 5, 10, or $15 \mathrm{mmHg}$ [22], and whether paired values for HR were within 3,5 , or 8 beats per minute (BPM). We determined whether the test device passed the ESH-IP validation protocol. Part 1 of the validation process concerns the number of differences allowed in the specified ranges of each measure (SBP, DBP, and HR) for comparisons of individual measurements between devices (99 measurements) [22]. Part 2 concerns the comparisons between devices of each measure for individual participants (33) [22].

Moreover, we produced Bland-Altman plots [27,28] to display the agreement between the two devices (the iHealth Track and the Omron M3 Intellisense). These plots show the difference between each pair of measurements on the y-axis against the mean of each pair of measurements on the $\mathrm{x}$-axis (for SBP, DBP, and HR).

\section{Results}

\section{Participants}

Of the 34 participants we recruited, 33 completed the study successfully (one was excluded for device failure). The 33 participants included 20 men and 13 women. Table 1 shows a summary of their biometric characteristics.

Table 1. Participants' biometric characteristics.

\begin{tabular}{lllllll}
\hline Variables & \multicolumn{2}{l}{ Total sample (N=33) } & \multicolumn{2}{l}{ Males (N=20) } & & \multicolumn{2}{l}{ Females (N=13) } \\
& Mean $(\mathrm{SD})$ & Range & Mean (SD) & Range & Mean (SD) & Range \\
\hline Age (years) & $71.24(11.76)$ & $47.0-88.0$ & $70.25(11.42)$ & $47.0-85.0$ & $72.77(12.57)$ & $47.0-88.0$ \\
Weight $(\mathrm{kg})$ & $70.48(15.87)$ & $46.0-101.0$ & $70.18(12.95)$ & $47-100.0$ & $70.94(20.16)$ & $46.0-101.0$ \\
Height $(\mathrm{cm})$ & $162.24(9.87)$ & $141.0-180.0$ & $167.10(4.58)$ & $160.0-180.0$ & $154.77(11.24)$ & $141.0-174.0$ \\
BMI $\left(\mathrm{kg} / \mathrm{m}^{2}\right)$ & $26.95(6.72)$ & $18.0-44.0$ & $25.07(4.08)$ & $18.0-33.0$ & $29.84(8.90)$ & $19.0-44.0$ \\
Arm circumference $(\mathrm{mm})$ & $265.0(33.12)$ & $220.0-350.0$ & $264.75(26.13)$ & $220.0-320.0$ & $265.0(33.12)$ & $220.0-350.0$ \\
\hline
\end{tabular}

\section{Blood Pressure Measurements}

The iHealth Track BP device validation results were taken in accordance with the ESH-IP2. The mean differences between the reference standard and test devices were 3.27 (SD 2.99) $\mathrm{mmHg}$ for SBP and 3.59 (SD 5.28) $\mathrm{mmHg}$ for DBP. In 90 out of 99 SBP and 89 out of 99 DBP comparisons between the devices, measurement differences were within $5 \mathrm{mmHg}$, exceeding the ESH-IP thresholds (>72 comparisons for SBP and $>64$ comparisons for DBP). Additionally, in 95 out of 99 SBP and 94 out of 99 DBP comparisons between the devices, measurement differences were within $10 \mathrm{mmHg}$, also exceeding 
the ESH-IP thresholds (>86 comparisons for SBP and >80 comparisons for DBP). Moreover, in 98 out of 99 SBP and 94 out of 99 DBP comparisons between the devices, measurement differences were within $15 \mathrm{mmHg}$, which again surpasses the ESH-IP thresholds ( $>95$ comparisons for SBP and $>92$ comparisons for DBP). Therefore, the iHealth Track passed part 1 of the validation protocol for BP monitoring.

Regarding part 2 of the ESH-IP2, 31 out of 33 participants had at least two of the three comparisons between devices with measurement differences within $5 \mathrm{mmHg}$ for both SBP and DBP, exceeding the ESH-IP threshold (>23 participants). One participant had all three comparisons for both SBP and DBP with measurement differences greater than $5 \mathrm{mmHg}$, which is less than the ESH-IP maximum of 3 participants. Given these results, the iHealth Track also passed part 2 of the validation protocol for BP. Thus, because the iHealth Track passed parts 1 and 2 of the BP validation protocol, it passed part 3 of the protocol, overall validation.

\section{Heart Rate Measurements}

The validation findings for the iHealth Track HR monitoring device were taken according to the ESH-IP2. The mean difference between the reference standard and test devices was 2.18 BPM (SD 2.75). In comparisons between devices, 81 out of 99 pairs of measurements were within 3 BPM, 91 out of 99 were within 5 BPM, and 96 out of 99 were within 8 BPM. These results indicate that the iHealth Track passed part 1 of the validation protocol for HR.

Regarding part 2 of the ESH-IP2, 28 out of 33 patients had at least two of three comparisons between devices with measurement differences within 3 BPM, which exceeds the ESH-IP threshold (>23 participants). Only 2 participants had all three HR comparisons with measurement differences greater than 3 BPM, which is less than the ESH-IP maximum of 3 participants. Therefore, the iHealth Track passed part 2 of the HR validation protocol and, consequently, part 3 (overall validation) as well.

The Bland-Altman graphs (Figures 1-3) give further information on the performance of the iHealth Track device. The graphs show that the measurement differences between the devices were fairly constant across the ranges of SBP, DBP, and HR.

Figure 1. Bland-Altman graph of systolic blood pressure differences between the iHealth Track and the Omron M3.

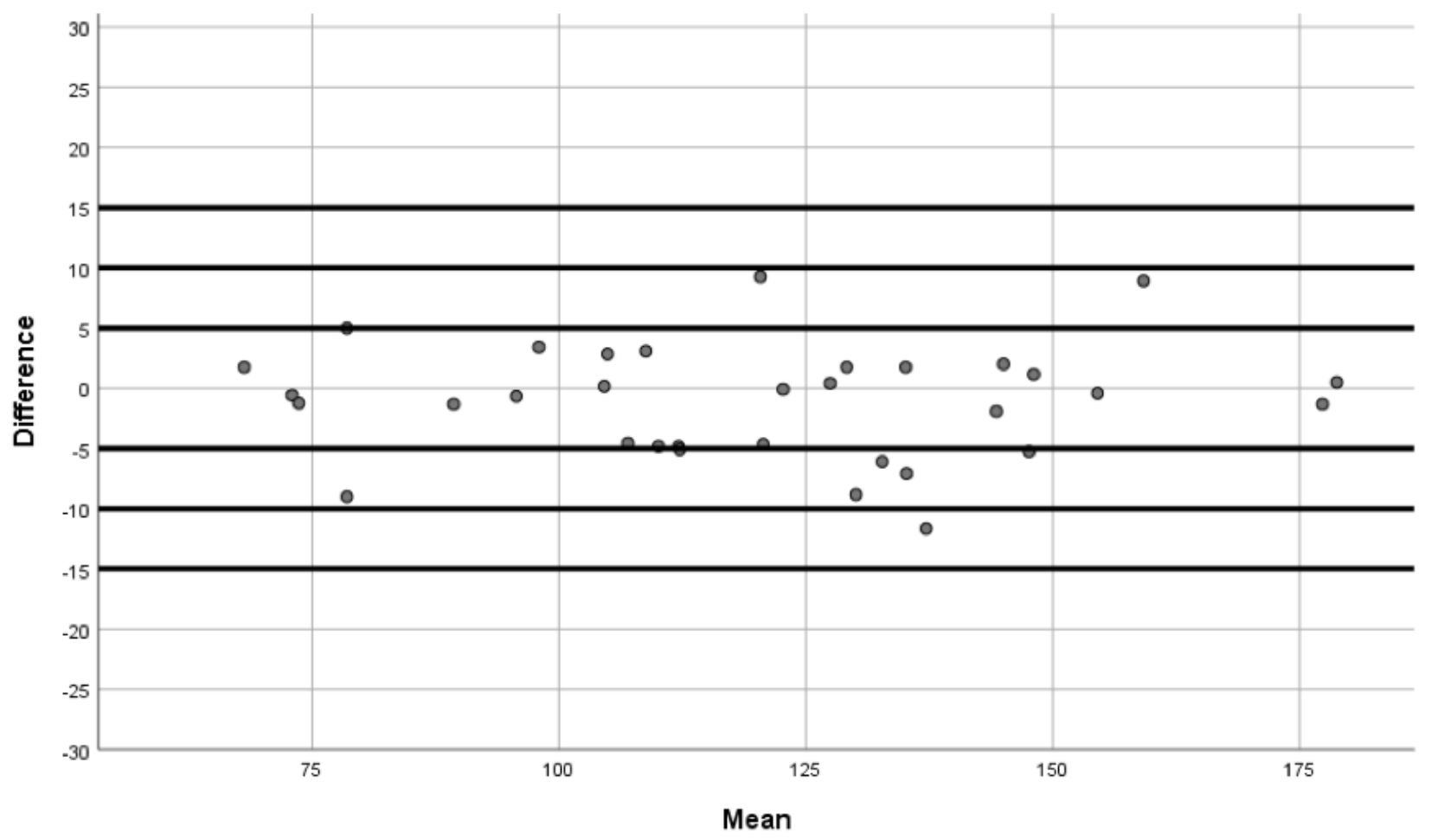


Figure 2. Bland-Altman graph for diastolic blood pressure differences between the iHealth Track and the Omron M3.

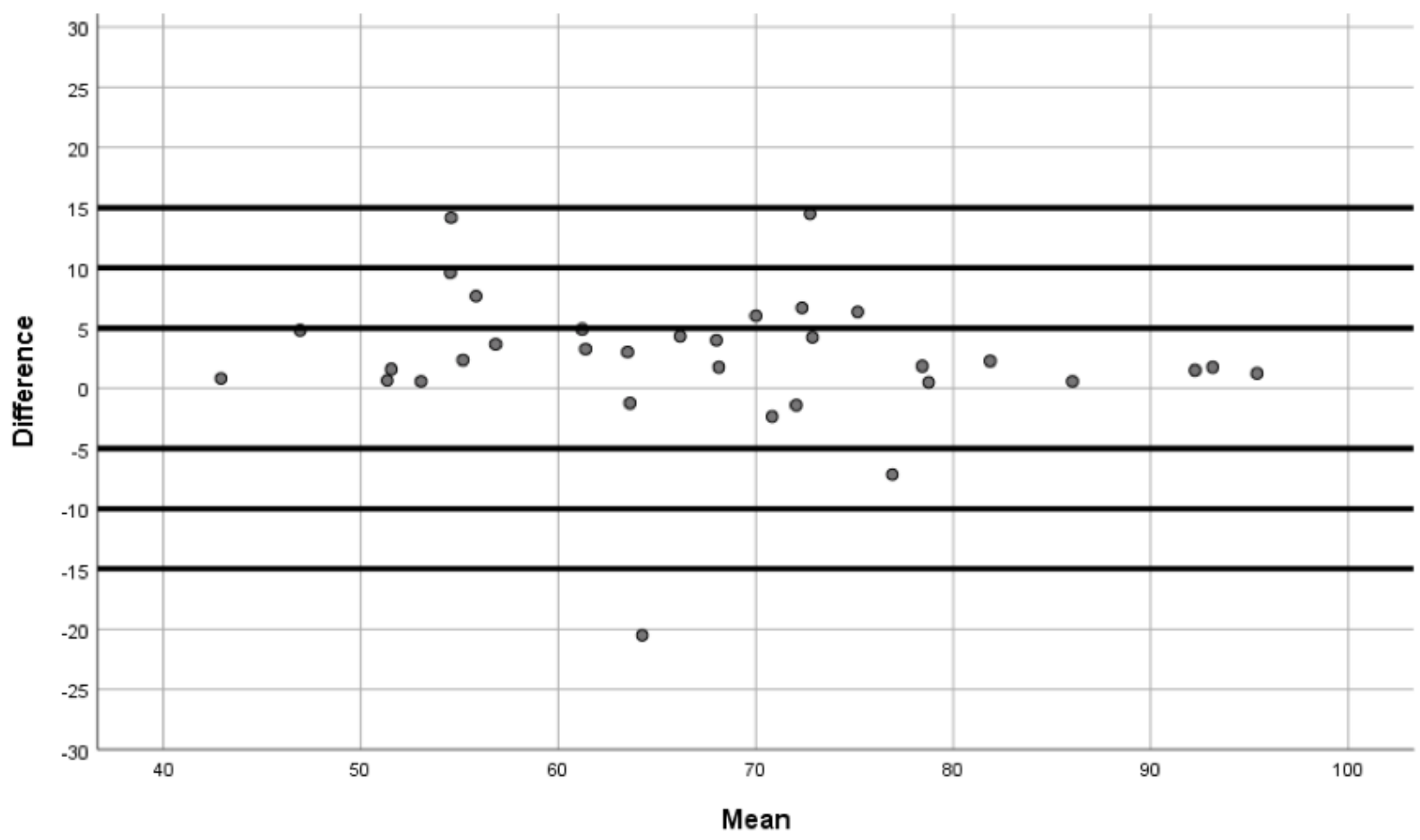

Figure 3. Bland-Altman graph for heart rate differences between the iHealth Track and the Omron M3.

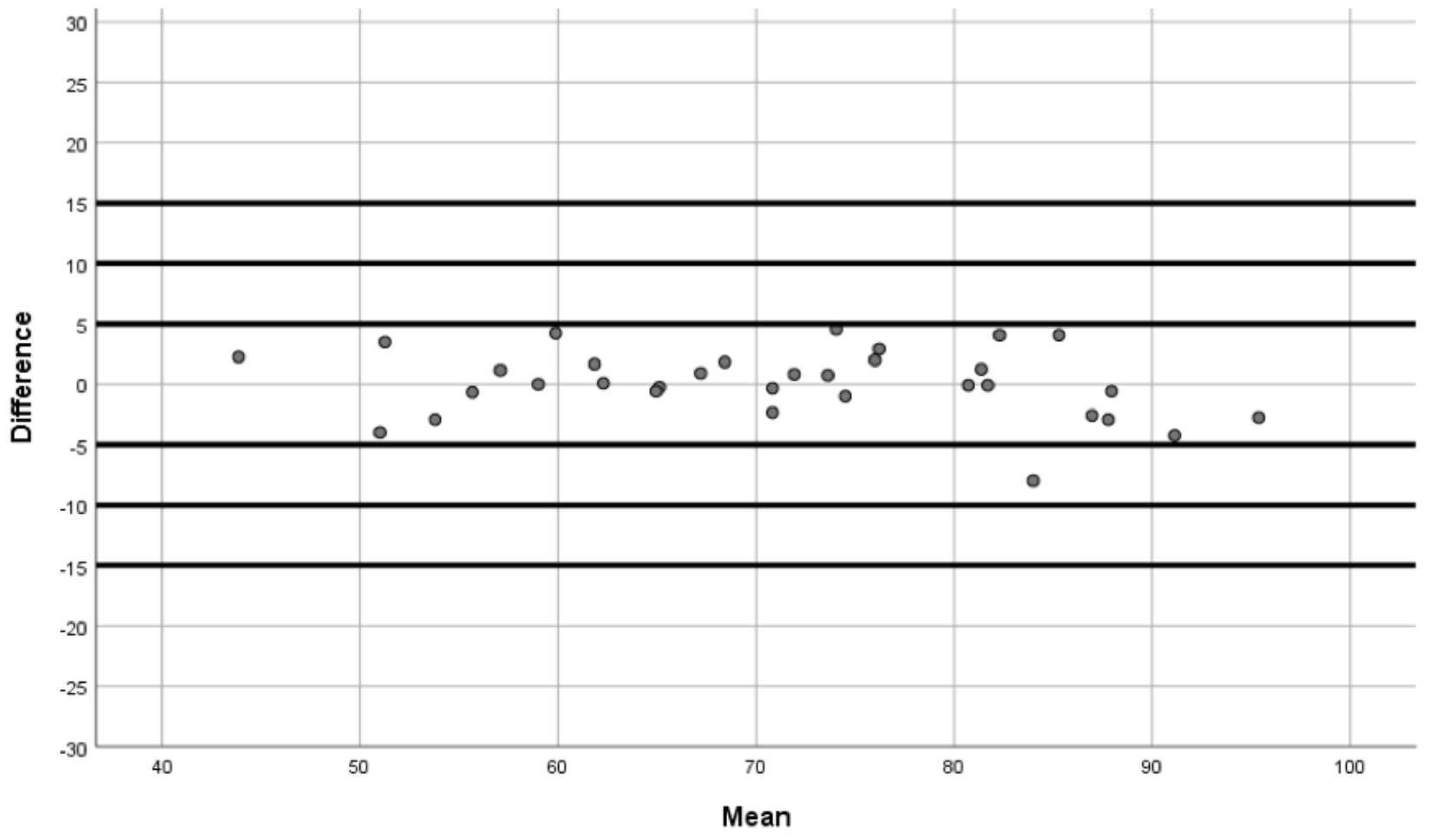

\section{Discussion}

This study is the first to validate the accuracy of the iHealth Track device for BP and HR recordings in patients with CKD. The results indicate that the iHealth Track, as used in renal patients, passed the ESH-IP2 validation requirements. We previously validated the iHealth Track device for the general population following ESH-IP2 [29].
This study showed two limitations. Although the iHealth Track has been validated in the general population and now in patients with CKD, we cannot necessarily extrapolate our results to other specific populations. In addition, patients with CKD have stiffer arteries than other people $[9,11,14]$. We did not investigate arterial stiffness, but it would be useful to assess it in future validation studies. 
The ESH-IP2 for home BP monitoring highlights the need for specific validation in patients with end-stage renal disease $[14,30]$ as strict control of hypertension is required in these patients $[9,14]$.

However, there are few devices that have been validated in patients with renal disease [26,31-34]. Akpolat et al [26] validated Omron M3 HEM-7051 in patients with CKD according to the ESH-IP2 revision. They used the mercury sphygmomanometer as their standard reference device and included 66 participants, rather than 33 . The results were similar to ours, since both studies passed the ESH-IP revision's two phases of validation. However, the number of differences included in the category of $5 \mathrm{mmHg}$ according to the ESH-IP2 were better for the iHealth Track for both SBP and DBP (ie, iHealth Track achieved higher differences than Omron). The differences obtained with the HRs cannot be contrasted as HR was not measured by Akpolat et al. Likewise, our findings cannot be compared with the rest of the validation studies found [31-34], since none followed the ESH-IP2 validation requirements. We believe that more validation studies for $\mathrm{BP}$ monitoring devices are necessary for patients with CKD.

The purpose of the ESH-IP2 was to simplify the previous protocols of the British Hypertension Society (BHS) [19] and the Association for the Advancement of Medical Instrumentation (AAMI) [20]. However, the protocol does have some shortcomings. First, the major limitation is that it is underpowered with only 33 participants (99 measures) required rather than the 85 participants (255 measures) required by the previous AAMI and BHS validation protocols $[19,20]$. Second, the ESH-IP2 does not indicate the number of validation studies needed to establish the accuracy of a device. According to some experts, at least two validation studies should be performed in different centers and in different populations before accepting the device as accurate [35]. Therefore, it is valuable to evaluate BP devices in diverse specific populations before they are used widely in clinics and homes. Third, the ESH-IP2 imposes certain gender requirements and limits validation studies to individuals older than 25 years who have BPs within specific ranges. Therefore, device accuracy remains unknown in children, adolescents, young adults, and patients with extreme BP values. Finally, the ESH-IP2 does not mention explicit criteria for validation in specific populations. Following the start of our study, in March 2019, the AAMI/ESH/ISO Universal Standard was published as the recommended standard for validation of BP measuring devices. [36]. This standard includes criteria for the validation of BP devices in specific populations. This will be considered in our future validations.

Our study is the first to show that the iHealth Track device meets the requirements of ESH-IP2 in patients with CKD. Future versions of the ESH-IP should include explicit criteria for validation in specific populations. Validation of this device would be valuable in other specific populations such as pregnant women, older adults, and patients with arrhythmias.

\section{Acknowledgments}

We thank the patients and medical staff from the Fresenius Medical Care clinic in Plasencia, especially Dr Alejandro Cives, nephrologist.

\section{Conflicts of Interest}

None declared.

\section{References}

1. Levin A, Stevens P, Bilous R, Coresh J, de Francisco ALM, de Jong PE, et al. Kidney disease: Improving global outcomes (KDIGO) CKD work group. KDIGO 2012 clinical practice guideline for the evaluation and management of chronic kidney disease. Kidney Int Suppl 2013 Jan. [doi: 10.1038/kisup.2012.73]

2. Zoccali C, Vanholder R, Massy ZA, Ortiz A, Sarafidis P, Dekker FW, et al. The systemic nature of CKD. Nat Rev Nephrol 2017 Jun;13(6):344-358. [doi: 10.1038/nrneph.2017.52] [Medline: 28435157]

3. Jha V, Garcia-Garcia G, Iseki K, Li Z, Naicker S, Plattner B, et al. Chronic kidney disease: global dimension and perspectives. The Lancet 2013 Jul;382(9888):260-272. [doi: 10.1016/S0140-6736(13)60687-X]

4. Stanifer JW, Kilonzo K, Wang D, Su G, Mao W, Zhang L, et al. Traditional medicines and kidney disease in low- and middle-income countries: opportunities and challenges. Semin Nephrol 2017 May;37(3):245-259. [doi: 10.1016/j.semnephrol.2017.02.005] [Medline: 28532554]

5. Eriksen BO, Stefansson VT, Jenssen TG, Mathisen UD, Schei J, Solbu MD, et al. Elevated blood pressure is not associated with accelerated glomerular filtration rate decline in the general non-diabetic middle-aged population. Kidney Int 2016 Aug;90(2):404-410. [doi: 10.1016/j.kint.2016.03.021] [Medline: 27188503]

6. Freedman BI, Cohen AH. Hypertension-attributed nephropathy: what's in a name? Nat Rev Nephrol 2016 Jan 10;12(1):27-36. [doi: 10.1038/nrneph.2015.172] [Medline: 26553514]

7. Muntner P, Anderson A, Charleston J, Chen Z, Ford V, Makos G, et al. Hypertension awareness, treatment, and control in adults with CKD: results from the Chronic Renal Insufficiency Cohort (CRIC) Study. Am J Kidney Dis 2010 Mar;55(3):441-451 [FREE Full text] [doi: 10.1053/j.ajkd.2009.09.014] [Medline: 19962808]

8. Agarwal R, Pappas MK, Sinha AD. Masked uncontrolled hypertension in CKD. JASN 2015 Jul 10;27(3):924-932. [doi: 10.1681/asn.2015030243] 
9. Romagnani P, Remuzzi G, Glassock R, Levin A, Jager KJ, Tonelli M, et al. Chronic kidney disease. Nat Rev Dis Primers 2017 Nov 23;3:17088. [doi: 10.1038/nrdp.2017.88] [Medline: 29168475]

10. Flynn JT, Mitsnefes M, Pierce C, Cole SR, Parekh RS, Furth SL, et al. Blood pressure in children with chronic kidney disease: a report from the Chronic Kidney Disease in Children study. Hypertension 2008 Oct;52(4):631-637 [FREE Full text] [doi: 10.1161/HYPERTENSIONAHA.108.110635] [Medline: 18725579 ]

11. Williams B, Mancia G, Spiering W, Agabiti Rosei E, Azizi M, Burnier M, et al. 2018 ESC/ESH Guidelines for the management of arterial hypertension: The Task Force for the management of arterial hypertension of the European Society of Cardiology and the European Society of Hypertension: The Task Force for the management of arterial hypertension of the European Society of Cardiology and the European Society of Hypertension. J Hypertens 2018 Oct;36(10):1953-2041. [doi: 10.1097/HJH.0000000000001940] [Medline: 30234752]

12. Sim JJ, Shi J, Kovesdy CP, Kalantar-Zadeh K, Jacobsen SJ. Impact of achieved blood pressures on mortality risk and end-stage renal disease among a large, diverse hypertension population. J Am Coll Cardiol 2014 Aug 12;64(6):588-597 [FREE Full text] [doi: 10.1016/j.jacc.2014.04.065] [Medline: 25104529]

13. Cheung AK, Rahman M, Reboussin DM, Craven TE, Greene T, Kimmel PL, et al. Effects of intensive BP control in CKD. J Am Soc Nephrol 2017 Sep 22;28(9):2812-2823 [FREE Full text] [doi: 10.1681/ASN.2017020148] [Medline: 28642330]

14. Parati G, Ochoa JE, Bilo G, Agarwal R, Covic A, Dekker FW, et al. Hypertension in chronic kidney disease part 2. Hypertension 2016 Jun;67(6):1102-1110. [doi: 10.1161/hypertensionaha.115.06896]

15. Uhlig K, Patel K, Ip S, Kitsios GD, Balk EM. Self-measured blood pressure monitoring in the management of hypertension: a systematic review and meta-analysis. Ann Intern Med 2013 Aug 06;159(3):185-194. [doi: 10.7326/0003-4819-159-3-201308060-00008] [Medline: 23922064]

16. Sharman JE, Howes FS, Head GA, McGrath BP, Stowasser M, Schlaich M, et al. Home blood pressure monitoring: Australian Expert Consensus Statement. J Hypertens 2015 Sep;33(9):1721-1728 [FREE Full text] [doi: 10.1097/HJH.0000000000000673] [Medline: 26136205]

17. Imai Y, Kario K, Shimada K, Kawano Y, Hasebe N, Matsuura H, et al. The Japanese Society of Hypertension guidelines for self-monitoring of blood pressure at home (second edition). Hypertens Res 2012 Aug;35(8):777-795. [doi: 10.1038/hr.2012.56] [Medline: 22863910]

18. Mancia G, Fagard R, Narkiewicz K, Redón J, Zanchetti A, Böhm M, et al. 2013 ESH/ESC Guidelines for the management of arterial hypertension: the Task Force for the management of arterial hypertension of the European Society of Hypertension (ESH) and of the European Society of Cardiology (ESC). J Hypertens 2013 Jul;31(7):1281-1357. [doi: 10.1097/01.hjh.0000431740.32696.cc] [Medline: 23817082]

19. O'Brien E, Petrie J, Littler W, de Swiet M, Padfield PL, Altman DG, et al. An outline of the revised British Hypertension Society protocol for the evaluation of blood pressure measuring devices. J Hypertens 1993 Jun;11(6):677-679. [doi: 10.1097/00004872-199306000-00013] [Medline: $\underline{8397248]}$

20. ANSI/AAMI/ISO 81060- 2:2013.: Association For The Advancement Of Medical Instrumentation Non-invasive sphygmomanometers — Part 2: Clinical investigation of automated measurement type URL: http://my.aami.org/ aamiresources/previewfiles/8106002 1306 preview.pdf

21. O'Brien E, Pickering T, Asmar R, Myers M, Parati G, Staessen J, et al. Working Group on Blood Pressure Monitoring of the European Society of Hypertension International Protocol for validation of blood pressure measuring devices in adults. Blood Press Monit 2002 Feb;7(1):3-17. [doi: 10.1097/00126097-200202000-00002] [Medline: 12040236]

22. O'Brien E, Atkins N, Stergiou G, Karpettas N, Parati G, Asmar R, et al. European Society of Hypertension International Protocol revision 2010 for the validation of blood pressure measuring devices in adults. Blood Press Monit 2010 Feb;15(1):23-38. [doi: 10.1097/MBP.0b013e3283360e98] [Medline: 20110786]

23. Stergiou GS, Alpert B, Mieke S, Asmar R, Atkins N, Eckert S, et al. A universal standard for the validation of blood pressure measuring devices. Journal of Hypertension 2018;36(3):472-478. [doi: 10.1097/hjh.0000000000001634]

24. Asociación Médica Mundial. 2013 Oct. Declaración de Helsinki de la Amm - principios éticos para las investigaciones médicas en seres humanos URL: https://www.wma.net/es/policies-post/declaracion-de-helsinki-de-la-amm-principioseticos-para-las-investigaciones-medicas-en-seres-humanos/ [accessed 2019-03-04]

25. Asmar R, Khabouth J, Topouchian J, El Feghali R, Mattar J. Validation of three automatic devices for self-measurement of blood pressure according to the International Protocol: The Omron M3 Intellisense (HEM-7051-E), the Omron M2 Compact (HEM 7102-E), and the Omron R3-I Plus (HEM 6022-E). Blood Press Monit 2010 Feb;15(1):49-54. [doi: 10.1097/MBP.0b013e3283354b11] [Medline: 20032779]

26. Akpolat T, Erdem E, Aydogdu T. Validation of the Omron M3 Intellisense (HEM-7051-E) upper arm blood pressure monitor, for self-measurement, according to the European Society of Hypertension International Protocol revision 2010 in a stage 3-5 chronic kidney disease population. Kidney Blood Press Res 2012;35(2):82-88 [FREE Full text] [doi: 10.1159/000330719] [Medline: 21912183]

27. Bland JM, Altman D. Statistical methods for assessing agreement between two methods of clinical measurement. The Lancet 1986 Feb;327(8476):307-310. [doi: 10.1016/S0140-6736(86)90837-8]

28. Bland J, Altman D. Comparing methods of measurement: why plotting difference against standard method is misleading. The Lancet 1995 Oct;346(8982):1085-1087. [doi: 10.1016/s0140-6736(95)91748-9] 
29. Mazoteras-Pardo V, Becerro-De-Bengoa-Vallejo R, Losa-Iglesias ME, López-López D, Palomo-López P, Rodríguez-Sanz $\mathrm{D}$, et al. Validation in the general population of the iHealth track blood pressure monitor for self-measurement according to the European Society of Hypertension International Protocol Revision 2010: descriptive investigation. JMIR Mhealth Uhealth 2019 Mar 19;7(3):e131377 [FREE Full text] [doi: 10.2196/13137] [Medline: 30888331]

30. Parati G, Stergiou GS, Asmar R, Bilo G, de Leeuw P, Imai Y, et al. European Society of Hypertension practice guidelines for home blood pressure monitoring. J Hum Hypertens 2010 Dec 3;24(12):779-785. [doi: 10.1038/jhh.2010.54] [Medline: 20520631]

31. Thompson AM, Eguchi K, Reznik ME, Shah SS, Pickering TG. Validation of an oscillometric home blood pressure monitor in an end-stage renal disease population and the effect of arterial stiffness on its accuracy. Blood Pressure Monitoring 2007;12(4):227-232. [doi: 10.1097/mbp.0b013e328108f544]

32. Peixoto AJ, Gray TA, Crowley ST. Validation of the SpaceLabs 90207 ambulatory blood pressure device for hemodialysis patients. Blood Pressure Monitoring 1999;4(5):217-221. [doi: 10.1097/00126097-199910000-00003]

33. Semret M, Zidehsarai M, Agarwal R. Accuracy of oscillometric blood pressure monitoring with concurrent auscultatory blood pressure in hemodialysis patients. Blood Press Monit 2005 Oct;10(5):249-255. [doi: 10.1097/01.mbp.0000172713.28029.84] [Medline: 16205443]

34. Czarkowski M, Staszków M, Kostyra K, Shebani Z, Niemczyk S, Matuszkiewicz-Rowińska J. Determining the accuracy of blood pressure measurement by the Omron HEM-907 before and after hemodialysis. Blood Press Monit 2009 Oct;14(5):232-238. [doi: 10.1097/mbp.0b013e328331d5b5] [Medline: 19938337]

35. Topouchian J, Agnoletti D, Blacher J, Youssef A, Ibanez I, Khabouth J, et al. Validation of four automatic devices for self-measurement of blood pressure according to the international protocol of the European Society of Hypertension. Vasc Health Risk Manag 2011;7:709-717 [FREE Full text] [doi: 10.2147/VHRM.S27193] [Medline: 22174581]

36. Stergiou GS, Palatini P, Asmar R, Ioannidis JP, Kollias A, Lacy P, et al. Recommendations and Practical Guidance for performing and reporting validation studies according to the Universal Standard for the validation of blood pressure measuring devices by the Association for the Advancement of Medical Instrumentation/European Society of Hypertension/International Organization for Standardization (AAMI/ESH/ISO). J Hypertens 2019 Mar;37(3):459-466. [doi: 10.1097/HJH.0000000000002039] [Medline: $\underline{\text { 30702492] }}$

\section{Abbreviations}

AAMI: Association for the Advancement of Medical Instrumentation

BHS: British Hypertension Society

BP: blood pressure

BPM: beats per minute

CKD: chronic kidney disorder

D: diastolic

ESH-IP2: Hypertension International in European Society protocol 2010

HR: heart rate

ISO: International Organization for Standardization

S: systolic

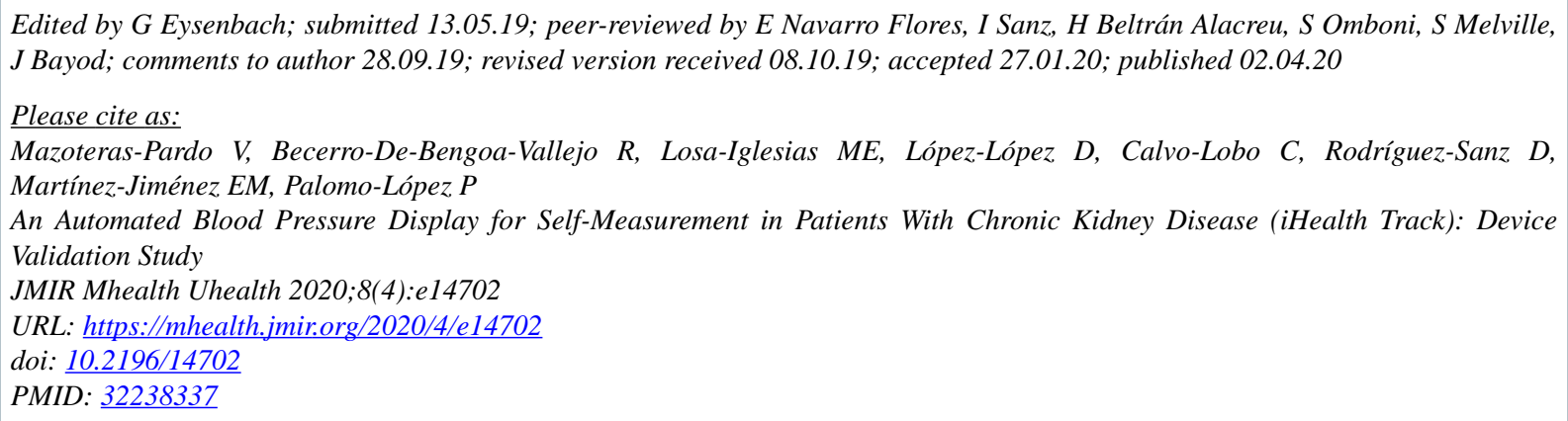

(CVictoria Mazoteras-Pardo, Ricardo Becerro-De-Bengoa-Vallejo, Marta Elena Losa-Iglesias, Daniel López-López, César Calvo-Lobo, David Rodríguez-Sanz, Eva María Martínez-Jiménez, Patricia Palomo-López. Originally published in JMIR mHealth and uHealth (http://mhealth.jmir.org), 02.04.2020. This is an open-access article distributed under the terms of the Creative Commons Attribution License (https://creativecommons.org/licenses/by/4.0/), which permits unrestricted use, distribution, and 
reproduction in any medium, provided the original work, first published in JMIR mHealth and uHealth, is properly cited. The complete bibliographic information, a link to the original publication on http://mhealth.jmir.org/, as well as this copyright and license information must be included. 